\title{
Mixed convection heat transfer over a non-linear stretching surface with variable fluid properties
}

\author{
K.V. Prasad ${ }^{\text {a }}$, K. Vajravelu ${ }^{\text {b,* }}$, P.S. Datti ${ }^{\mathrm{c}}$ \\ a Department of Mathematics, Central College Campus, Bangalore University, Bangalore 560001 , India \\ ${ }^{\mathrm{b}}$ Department of Mathematics, University of Central Florida, Orlando, FL 32816, USA \\ c T.I.F.R. Centre for Applicable Mathematics, Sharada Nagar, Yelahanka New Town, Bangalore 560 065, India
}

\section{A R T I C L E I N F O}

\section{Article history:}

Received 3 August 2009

Received in revised form

9 December 2009

Accepted 10 December 2009

\section{Keywords:}

Boundary layers

Variable viscosity

Variable thermal conductivity

Mixed convection

Stretching sheet

Similarity solution

Skin friction

Wall temperature gradient

\begin{abstract}
A B S T R A C T
This article presents a numerical solution for the steady two-dimensional mixed convection MHD flow of an electrically conducting viscous fluid over a vertical stretching sheet, in its own plane. The stretching velocity and the transverse magnetic field are assumed to vary as a power function of the distance from the origin. The temperature dependent fluid properties, namely, the fluid viscosity and the thermal conductivity are assumed to vary, respectively, as an inverse function of the temperature and a linear function of the temperature. A generalized similarity transformation is introduced to study the influence of temperature dependent fluid properties. The transformed boundary layer equations are solved numerically, using a finite difference scheme known as Keller Box method, for several sets of values of the physical parameters, namely, the stretching parameter, the temperature dependent viscosity parameter, the magnetic parameter, the mixed convection parameter, the temperature dependent thermal conductivity parameter and the Prandtl number. The numerical results thus obtained for the flow and heat transfer characteristics reveal many interesting behaviors. These behaviors warrant further study of the effects of the physical parameters on the flow and heat transfer characteristics. Here it may be noted that, in the case of the classical Navier-Stokes fluid flowing past a horizontal stretching sheet, McLeod and Rajagopal (1987) [42] showed that there exist an unique solution to the problem. This may not be true in the present case. Hence we would like to explore the non-uniqueness of the solution and present the findings in the subsequent paper.
\end{abstract}

(c) 2009 Elsevier Ltd. All rights reserved.

\section{Introduction}

The study of the hydromagnetic flow of an electrically conducting fluid past a heated vertical surface has attracted the interest of many researchers due to its extensive applications to many engineering and industrial problems such as hot rolling, wire drawing, spinning of filaments, metal extrusion, plasma studies, petroleum industries, MHD power generator, cooling of nuclear reactors, the boundary layer control in aerodynamics and crystal growth [1-3]. Until recently, this study has been largely concerned with the flow and heat transfer characteristics in various physical situations [4-9]. Watanabe and Pop [4] investigated the heat transfer in thermal boundary layers of magnetohydodynamic Newtonian/non-Newtonian flows over a flat plate.

Andersson [5] presented an exact analytical solution of the MHD flow of a Walters liquid B past a stretching sheet. Abel et al. [6] extended to study the effects of magnetic field on viscoelastic fluid flow and heat transfer over a stretching sheet with internal

\footnotetext{
* Corresponding author. Tel.: +1 407823 5089; fax: +1 4078236253.

E-mail address: vajravel@pegasus.cc.ucf.edu (K. Vajravelu).
}

heat generation/absorption. Datti et al. [7] further extended the work of Abel et al. [6] to flow and heat transfer with thermal radiation in the presence of variable thermal conductivity over a non-isothermal stretching sheet. Abo-Eldahab and Salem [8] studied the influence of transverse magnetic field on the flow and heat transfer of an electrically conducting fluid over a stretching sheet with a uniform free stream. Prasad et al. [9] studied the effect of variable thermal conductivity on MHD flow and heat transfer of a power-law fluid over a non-isothermal stretching sheet with internal heat generation/absorption. Prasad and Vajravelu [10] examined the MHD flow and heat transfer phenomena in a power law fluid over a porous stretching surface, taking into account the internal heat generation/absorption, viscous dissipation, work done by stress, variable thermal conductivity, and thermal radiation. In Ref. [10], the solutions presented in some figures do not seem to satisfy the asymptotic conditions at infinity: This happened due to the magnification of the figures. In the present paper, the attention has been paid to avoid it.

In many practical situations, the material moves in a quiescent fluid with the fluid flow being induced by the motion of the solid 


\begin{tabular}{|c|c|c|c|}
\hline \multicolumn{2}{|c|}{ Nomenclature } & $x$ & horizontal distance \\
\hline$a$ & constant & $u$ & velocity in $x$-direction \\
\hline$b$ & stretching rate, positive constant & $u_{w}$ & velocity of the sheet \\
\hline$B(x)$ & magnetic field & $v$ & velocity in $y$-direction \\
\hline$C_{f}$ & skin friction & \multirow{2}{*}{\multicolumn{2}{|c|}{ Greek symbols }} \\
\hline $\begin{array}{l}C_{p} \\
f\end{array}$ & $\begin{array}{l}\text { specific heat at constant pressure } \\
\text { dimensionless velocity variable }\end{array}$ & & \\
\hline $\mathrm{Gr}_{x}$ & Grashof number & $\Delta T$ & sheet temperature \\
\hline$h(x)$ & heat transfer coefficient & $\varepsilon$ & small parameter \\
\hline$k(T)$ & thermal conductivity & $\eta$ & similarity variable \\
\hline$k_{\infty}$ & thermal conductivity far away from the sheet & $\gamma$ & kinematic viscosity \\
\hline$m$ & index of power law velocity & $\beta_{0}$ & the coefficient of thermal expansion \\
\hline$M n$ & magnetic parameter & $\beta$ & stretching parameter \\
\hline $\mathrm{Nu}_{x}$ & Nusselt number & $\mu$ & dynamic viscosity \\
\hline $\operatorname{Pr}$ & Prandtl number & $\mu_{\infty}$ & constant value of dynamic viscosity \\
\hline$q_{w}$ & local heat flux at the sheet & $\psi$ & stream function \\
\hline $\operatorname{Re}_{x}$ & local Reynolds number & $\rho$ & density \\
\hline$S$ & dummy parameter & $\rho_{\infty}$ & constant fluid density \\
\hline$T$ & temperature variable & $\sigma$ & electric conductivity \\
\hline$T_{r}$ & transformed reference temperature & $\tau_{x y}$ & shear stress \\
\hline$T_{w}$ & given temperature at the sheet & $\theta$ & dimensionless temperature variable \\
\hline$T_{\infty}$ & $\begin{array}{l}\text { constant temperature of the fluid far away from the } \\
\text { sheet }\end{array}$ & $\begin{array}{l}\theta_{r} \\
\lambda\end{array}$ & $\begin{array}{l}\text { transformed dimensionless reference temperature } \\
\text { mixed convection parameter }\end{array}$ \\
\hline
\end{tabular}

material and by the thermal buoyancy. Therefore, the resulting flow and thermal fields are determined by the two mechanisms, namely, the surface motion and the buoyancy force. It is well known that the buoyancy forces stemming from the heating or cooling of the continuous stretching sheets alter the flow and thermal fields and thereby the heat transfer characteristics of the manufacturing process. However, the buoyancy force effects were not considered in the aforementioned studies. Effects of thermal buoyancy force on Newtonian flow and heat transfer over a stretching sheet have been reported by several investigators. Combined forced and free convection in boundary layers adjacent to a continuous horizontal sheet maintained at a constant temperature and moving with a constant velocity was investigated numerically by Chen and Stobel [11]. A similar analysis was carried out by Moutsoglou and Chen [12] for an inclined continuous sheet with uniform wall temperature or uniform surface heat flux. Numerical studies including the effects of buoyancy force conjugate conduction and thermal radiation have been reported by Karwe and Jaluria [13] for a continuous flat plate moving at a uniform speed. Malarvizi et al. [14] studied the free and mixed convection about a vertical plate with prescribed temperature or heat flux. Vajravelu [15] analyzed the combined free and forced convection heat transfer at a stretching sheet with variable surface temperature and suction or blowing. Chen [16] explored the effect of thermal buoyancy on flow past a vertical, continuous stretching sheet on which the velocity and temperature are assumed to vary in a power law form. Ali and Al-Yousef [17] considered the effects of mixed convection on boundary layer adjacent to a continuously moving upward vertical surface with suction or injection at the surface for general boundary conditions of power law velocity and temperature distributions. Recently several researchers have focused their attention to the problem of free and forced convection in MHD flow due to the fact that convection induced by the simultaneous action of buoyancy forces resulting from the thermal diffusion is of considerable interest in nature and in any industrial applications. Vajravelu and
Hadjinicolaou [18] carried out an analysis of the flow and heat transfer characteristics in an electrically conducting fluid near an isothermal stretching sheet. El-Hakim et al. [19] presented an analysis of MHD free convection heat transfer of an electrically conducting micropolar fluid past a semi infinite plate including the effects of viscosity and joule heating. Chamkha [20] and AboEldahab [21] considered the problems related to hydromagnetic three-dimensional flow on a stretching surface. Ishak et al. [22] studied the effects of a uniform magnetic filed on the stagnation point towards a vertical sheet.

In all the above mentioned works, the thermo-physical properties of the ambient fluid were assumed to be constant. However, it is well known that (Herwig and Wickern [23], Lai and Kulacki [24], Takhar [25], Pop et al. [26], Hassanien et al. [27], Subhas Abel et al. [28], Seedbeck [29], Ali [30], Andersson and Aarseth [31] Chaim [32]) these physical properties may vary with temperature, especially the fluid viscosity and the thermal conductivity. For lubricating fluids heat generated by internal friction and the corresponding rise in the temperature affects the physical properties of the fluid and the properties of the fluid may no longer be assumed as constant. Increase in temperature leads to an increase in the transport phenomena: There by reducing the physical properties across the thermal boundary layer and hence the heat transfer at the wall is also affected. Therefore to predict the flow and heat transfer rates, it is necessary to account for the variable fluid properties. In view of this, the problem studied here extends the work of Vajravelu [33], by considering the temperature dependent variable fluid properties over a vertical non-linear stretching sheet. The coupled non-linear partial differential equations governing the problem are reduced to a system of coupled highly non-linear ordinary differential equations by applying a suitable similarity transformation. The resultant boundary value problem is then converted into the system of six simultaneous equations of first-order for six unknowns. The system of equations is then solved by Keller Box method. Numerical computation has been carried out for temperature 
and horizontal velocity profiles, Nusselt number and skin friction coefficient. The effects of variable viscosity, variable thermal conductivity, stretching parameter, magnetic parameter, mixed convection parameter, and the Prandtl number on the flow behavior and heat transfer process are presented and discussed.

\section{Mathematical formulation of the problem}

The mathematical model considered here, is a viscous, incompressible, steady, two-dimensional mixed convection boundary layer flow due to a vertical heated sheet with variable fluid properties in a quiescent and electrically conducting fluid in the presence of a transverse magnetic field $B(x)$ as shown in Fig. 1. The origin is located at the slit through which the sheet is drawn. The $x$ axis is taken in the direction of the flow (that is, along the sheet) and the $y$-axis is normal to it. Two equal and opposite forces are applied along the $x$-axis so that the wall is stretched, keeping the origin fixed in the fluid with ambient temperature $T_{\infty}$. The continuous stretching surface is assumed to have power law velocity $u=u_{w}=b x^{m}$, where $b$ is a constant, $x$ denotes the distance from the slit and $m$ is an exponent. Here, we assume that the induced magnetic field produced by the motion of an electrically conducting fluid is

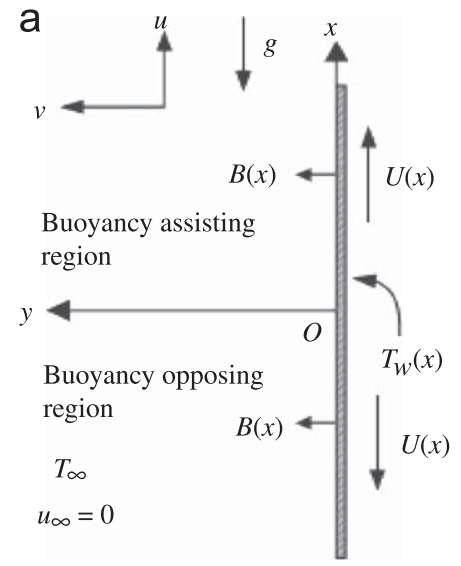

b

i
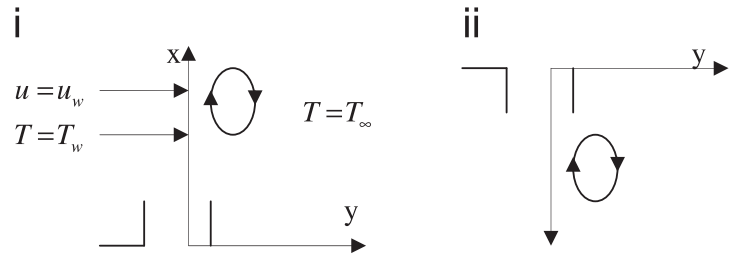

$$
\begin{gathered}
\theta_{r}<0, \text { for liquid, } \theta_{r}>1, \text { for gases } \\
T_{w}>T_{\infty}
\end{gathered}
$$

$\theta_{r}<0$, for liquid, $\theta_{r}>1$, for gases $T_{w}>T_{\infty}$

iii

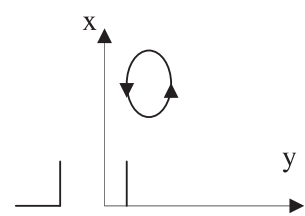

iv

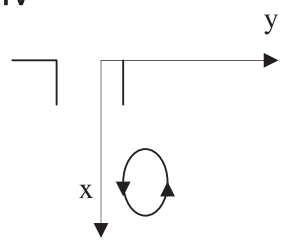

$\theta_{r}>1$, for liquid, $\theta_{r}<0$, for gases. $T_{w}<T_{\infty}$

$\theta_{r}>1$, for liquid, $\theta_{r}<0$, for gases. $T_{w}<T_{\infty}$

Fig. 1. (a) Schematic of mixed convection heat transfer from a stretching surface. (b) Schematic of the physical problem of a moving surface from a slot. negligible. This assumption is valid for small magnetic Reynolds number. Further, since there is no external electric field, the electric field due to polarization of charges is negligible. The viscous dissipation and the Ohmic heating terms are not included in the energy equation since they are generally small. Under these assumptions and invoking the usual boundary layer approximation along with the Boussinesq approximations, the basic equations governing the convective flow and heat transfer in the presence of variable fluid properties (i.e., fluid viscosity and thermal conductivity) are

$\frac{\partial u}{\partial x}+\frac{\partial v}{\partial y}=0$

$u \frac{\partial u}{\partial x}+v \frac{\partial u}{\partial y}=\frac{1}{\rho_{\infty}} \frac{\partial}{\partial y}\left(\mu \frac{\partial u}{\partial y}\right)-\frac{\sigma B^{2}(x)}{\rho_{\infty}} u \pm g \beta_{0}\left(T-T_{\infty}\right)$,

$\rho_{\infty} c_{\mathrm{p}}\left(u \frac{\partial T}{\partial x}+v \frac{\partial T}{\partial y}\right)=\frac{\partial}{\partial y}\left(k(T) \frac{\partial T}{\partial y}\right)$,

where $u$ and $v$ are the velocity components in the stream wise $x$ and cross-stream $y$ directions, respectively. Here $\rho_{\infty}$ is the constant fluid density and $\mu$ is the coefficient of viscosity which is considered to vary as an inverse function of temperature (Lai and Kulacki [24]) as $\frac{1}{\mu}=\frac{1}{\mu_{\infty}}\left[1+\delta\left(T-T_{\infty}\right)\right]$

i.e., $\quad \frac{1}{\mu}=a\left(T-T_{r}\right)$,

where

$a=\frac{\delta}{\mu_{\infty}} \quad$ and $\quad T_{r}=T_{\infty}-\frac{1}{\delta}$

Here, both $a$ and $T_{r}$ are constants, and their values depend on the reference state and $\delta$, a small parameter reflecting a thermal property of the fluid. In general, $a>0$ corresponds to liquids and $a<0$ to gases when the temperature at the sheet $\left(T_{w}\right)$ is larger than that of temperature at far away from the sheet $\left(T_{\infty}\right) . T$ is the temperature, $\mu_{\infty}$ is the coefficient of viscosity far away from the sheet. To demonstrate further, the appropriateness of the Eq. (4) and the correlations between the viscosity and temperature for air and water are given below:

For air : $\frac{1}{\mu}=-123.2(T-742.6)$, based on $T_{\infty}=293 \mathrm{~K}\left(20^{\circ} \mathrm{C}\right)$,

and

For water : $\frac{1}{\mu}=-29.83(T-258.6)$, based on $T_{\infty}=288 \mathrm{~K}\left(15^{\circ} \mathrm{C}\right)$.

The reference temperatures thus selected for the co-relations are very practical in most applications. The viscosity of a liquid usually decreases with increasing temperature while it increases for gases, when $\left(T_{w}-T_{\infty}\right)$ is positive. $T$ is the temperature; $T_{\infty}$ and $\mu_{\infty}$ are the temperature and coefficient of viscosity far away from the sheet, respectively; $\sigma$ is the electrical conductivity; $B(x)$ is the strength of the variable magnetic field. The special form of magnetic field $B(x)=B_{0} x^{(m-1) / 2}$ is chosen to obtain a similarity solution. This form of $B(x)$ has also been considered by Anjali Devi and Thiyagarajan [35] and Chiam [34] in their MHD flows past a moving or fixed flat plate. The last term on the right hand side of the Eq. (2) represents the influence of thermal buoyancy force on the flow field. The "+" and "- " signs refer to the buoyancy assisting and buoyancy opposing flows, respectively. Fig. 1 provides the necessary information of such a flow field for a stretching vertical heated sheet with upper half of the flow field being assisted and the lower half of the flow field being opposed by the buoyancy force. For the assisting flow, the $x$-axis points upward in the direction of the stretching hot surface 
such that the stretching induced flow and the thermal buoyant flow assist each other. For the opposing flow, the $x$-axis points vertically downward in the direction of the stretching hot surface, but in this case the stretching induced flow and the thermal buoyant flow oppose each other. The reverse trend occurs if the sheet is cooled below the ambient temperature. $T$ is the temperature of the fluid, $C_{p}$ is the specific heat at constant pressure and $k(T)$ is the temperaturedependent thermal conductivity. We consider the temperaturedependent thermal conductivity relationship of the form (Chiam [32]):

$k(T)=k_{\infty}\left(1+\frac{\varepsilon}{\Delta T}\left(T-T_{\infty}\right)\right)$,

where $\Delta T=T_{w}-T_{\infty}, T_{w}$ is the sheet temperature, $\varepsilon$ is a small parameter and $k_{\infty}$ is thermal conductivity of the fluid far away from the sheet. Substituting Eqs. (4), (5), and (6) into Eqs. (2) and (3), we obtain

$u \frac{\partial u}{\partial x}+v \frac{\partial u}{\partial y}=\frac{1}{\rho_{\infty}} \frac{\partial}{\partial y}\left(\frac{\mu_{\infty}}{1+\delta\left(T-T_{\infty}\right)} \frac{\partial u}{\partial y}\right)-\frac{\sigma B^{2}(x)}{\rho} u \pm g \beta_{0}\left(T-T_{\infty}\right)$,
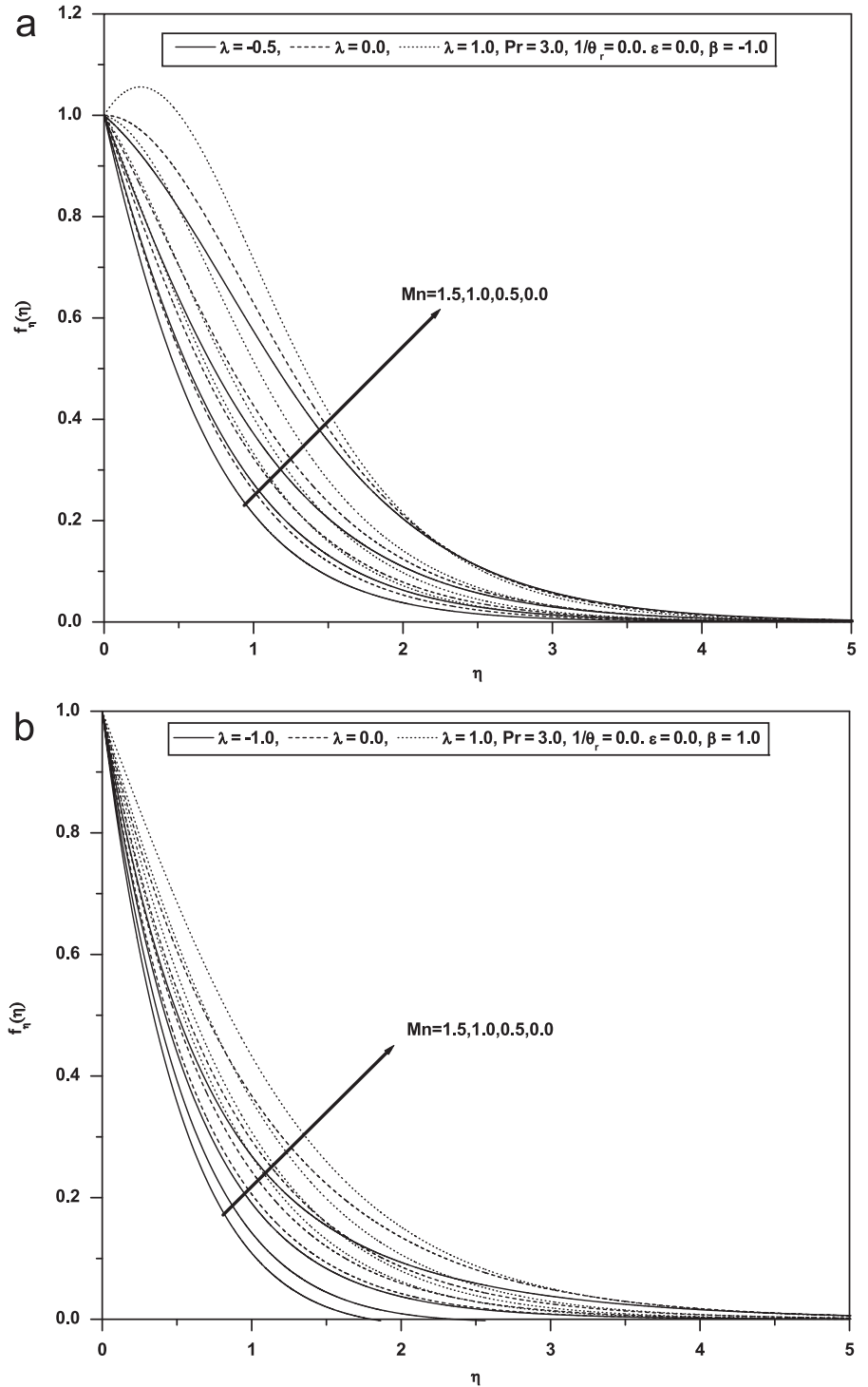

$\rho c_{p} u \frac{\partial T}{\partial x}+\left(\rho c_{p} v-\frac{k_{\infty} \varepsilon}{\Delta T} \frac{\partial T}{\partial y}\right)=\left(k_{\infty}\left(1+\frac{\varepsilon}{\Delta T}\left(T-T_{\infty}\right)\right)\right) \frac{\partial^{2} T}{\partial y^{2}}$.

From the above equation we see that the effect of the small parameter $\varepsilon$ is to enhance the thermal conductivity.

The appropriate boundary conditions on the velocity and the temperature fields are

$u=u_{w}=b x^{m}, \quad v=0, \quad T=T_{w} \quad$ at $y=0$,

$u \rightarrow 0, \quad T \rightarrow T_{\infty} \quad$ as $y \rightarrow \infty$

where $b$ is a constant known as stretching rate. It should be noted that the positive and negative $m$ indicate that the surface is accelerated or decelerated from the extruded slit, respectively. Now we transform the system of Eqs. (1)-(3) into a dimensionless form. To this end, let the dimensionless similarity variable be

$\eta=\frac{y}{x} \sqrt{\frac{m+1}{2}} \sqrt{\operatorname{Re}_{x}}$ where $\operatorname{Re}_{x}=\frac{u_{w}(x)}{\gamma_{\infty}} x$.

And the dimensionless stream function $f(\eta)$ and dimensionless temperature $\theta(\eta)$ be

$f(\eta)=\psi(x, y) /\left[u_{w} x\left(\operatorname{Re}_{x}\right)^{-1 / 2}\right]$,
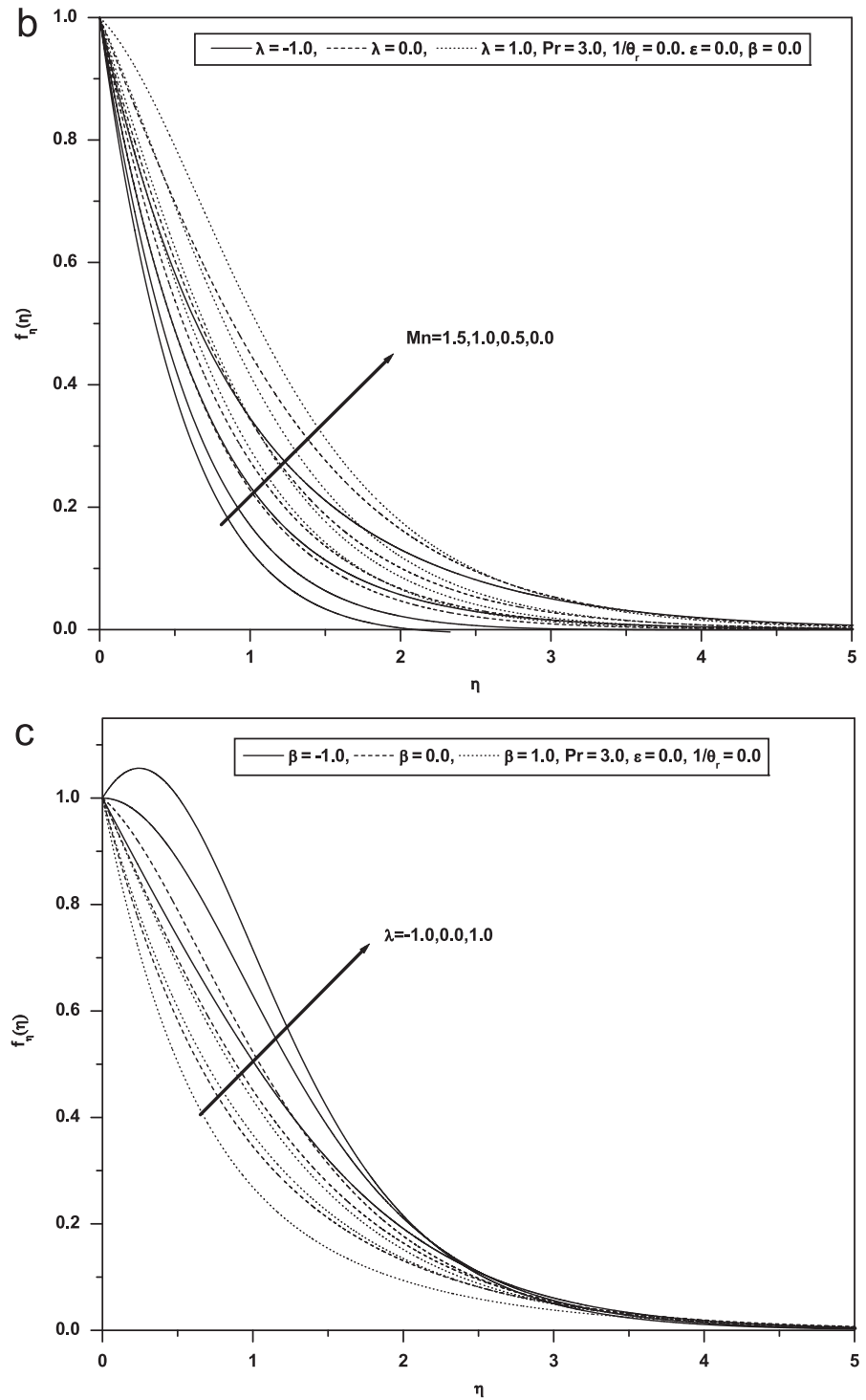

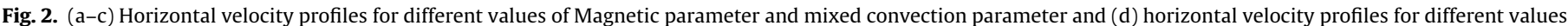
of mixed convection and stretching parameter. 
$\theta(\eta)=\left(T-T_{\infty}\right) /\left(T_{w}-T_{\infty}\right)$,

where the dimensionless stream function $\psi(x, y)$ identically satisfies the continuity Eq. (1) with

$u=\frac{\partial \psi}{\partial y} \quad$ and $\quad v=-\frac{\partial \psi}{\partial x}$.

By using the relations in (10)-(12), the momentum Eq. (7) and energy Eq. (8) can be written as

$\beta f_{\eta}^{2}(\eta)-f(\eta) f_{\eta \eta}(\eta)=\frac{1}{1-\frac{\theta(\eta)}{\theta_{\mathrm{r}}}}\left[f_{\eta \eta}(\eta)+\frac{f_{\eta \eta}(\eta) \theta_{\eta}(\eta)}{\theta_{\mathrm{r}}-\theta(\eta)}\right]-\operatorname{Mn} f_{\eta}(\eta)+\lambda \theta(\eta)$,

$[1+\varepsilon \theta(\eta)] \theta_{\eta \eta}(\eta)=-\varepsilon \theta_{\eta}^{2}(\eta)-\operatorname{Pr} f(\eta) \theta_{\eta}(\eta)$

and they are subjected to the boundary conditions

$f_{\eta}(\eta)=1, \quad f(\eta)=0, \quad \theta(\eta)=1 \quad$ at $\eta=0$,

$f_{\eta}(\eta)=0, \quad \theta(\eta)=0 \quad$ as $\eta \rightarrow \infty$.

Here, the subscript $\eta$ denotes the differentiation with respect to $\eta$. The parameters $\beta, \theta_{r}, M n, \lambda$ and Pr are, respectively, the stretching parameter, fluid viscosity parameter, magnetic parameter,

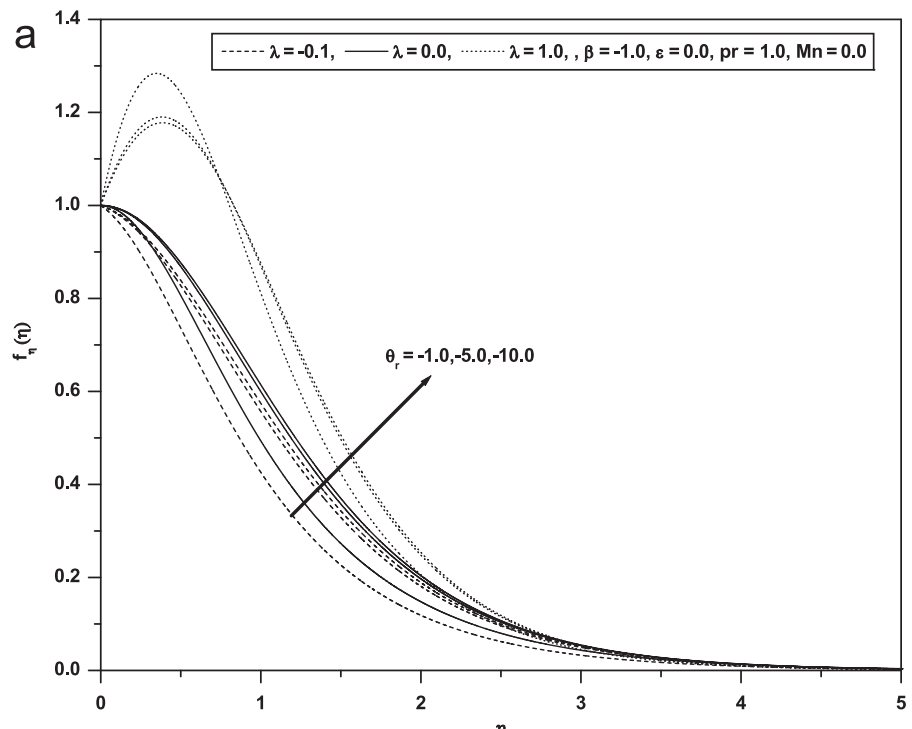

buoyancy or mixed convection parameter and the Prandtl number. They are defined as follows:

$\beta=\frac{2 m}{m+1}, \quad \theta_{r}=\frac{T_{r}-T_{\infty}}{T_{w}-T_{\infty}}=-\frac{1}{\delta\left(T_{w}-T_{\infty}\right)} \frac{2}{1+m}$,

$M n=\frac{2 \sigma B_{0}^{2}}{\rho_{\infty} b(m+1)}, \quad \operatorname{Pr}=\frac{\mu_{\infty} C_{p}}{k_{\infty}}, \quad \lambda=\frac{S G r_{x}}{\operatorname{Re}_{x}}$,

$S= \pm 1, \quad G r_{x}=\frac{g \beta\left(T_{w}-T_{\infty}\right)}{\gamma_{\infty}^{2}}$

Here, $\mathrm{Gr}_{x}$ is the local Grashof number. It is worth mentioning that $\lambda>0$ assists the flow and $\lambda<0$ opposes the flow; while $\lambda=0$ $\left(T_{w}=T_{\infty}\right)$ represent the case when the buoyancy forces are absent (pure forced convective flow). On the other hand, if $\lambda$ is of a significantly greater order of magnitude than one, the buoyancy forces will be predominant and the flow will essentially be free convective. Hence, combined convective flow exists when $\lambda=O(1)$. Eq. (14) shows that $\lambda$ is a function of $x$. The value of $\theta_{r}$ is determined by the viscosity of the fluid under consideration and the operating temperature difference. If $\theta_{r}$ is large, in other words, if $\left(T_{\infty}-T_{w}\right)$ is small, the effects of variable viscosity on the flow can be neglected. On other hand, for smaller values of $\theta_{r}$, either the fluid viscosity changes markedly with temperature or
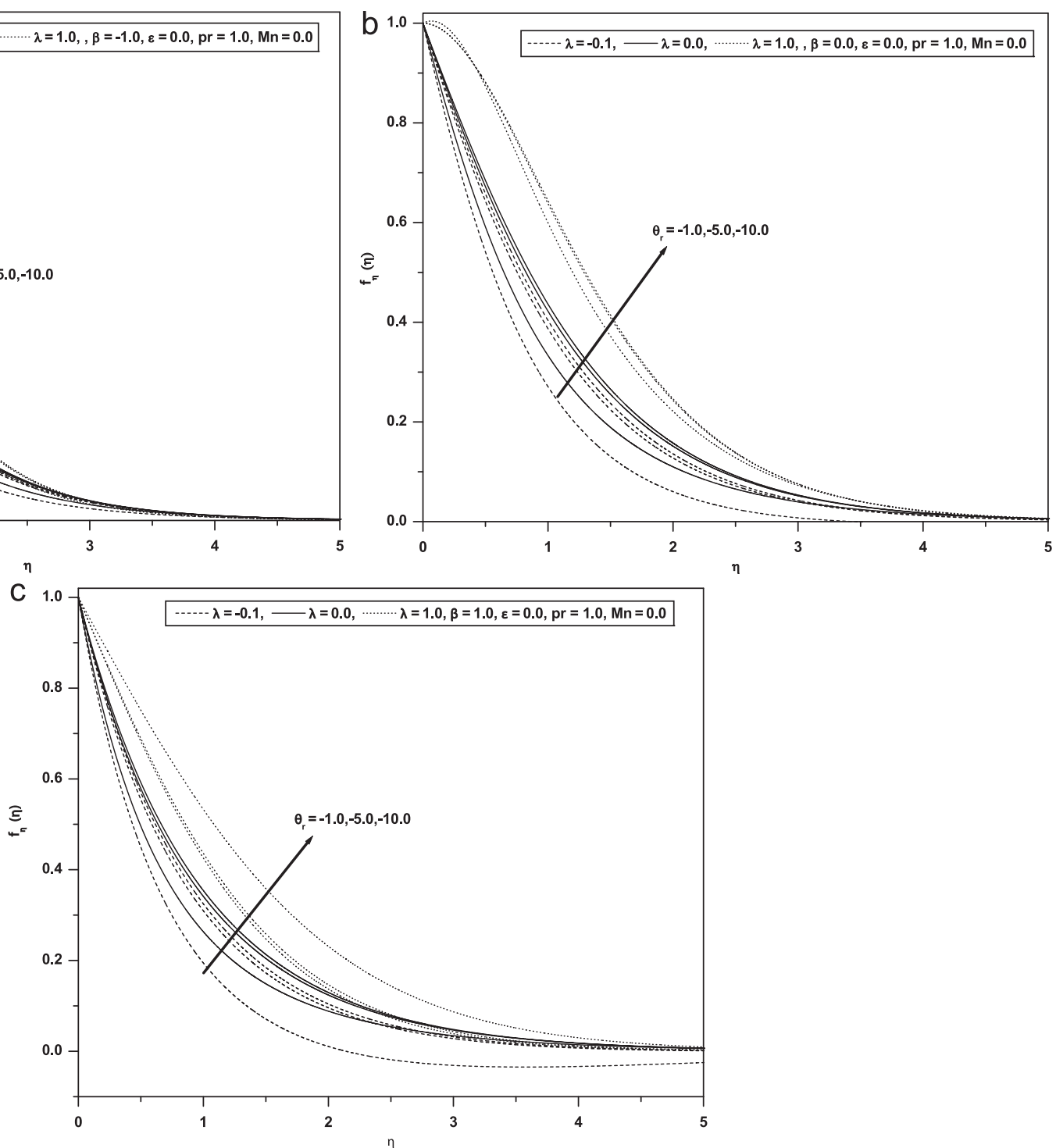

Fig. 3. $(a-c)$ Horizontal velocity profiles for different values of fluid viscosity parameter. 
the operating temperature difference is high. In either case, the variable fluid viscosity effect is expected to become very important. Also let us keep in mind that the liquid viscosity varies differently with temperature than in that of gas. Therefore it is important to note that $\theta_{r}$ is negative for liquids and positive for gases. It should be also noted that the velocity $u=u_{w}(x)$ used to define the dimensionless stream function $f(\eta)$ in the Eq. (11) and the local Reynolds number in (10) is the one that drives the fluid. This choice contrasts with conventional boundary layer analysis, in which the free stream velocity is taken as the velocity scale. Although the transformation defined in Eqs. (10) and (11) can be used for arbitrary variations of $u_{w}(x)$, the transformation results in a similarity problem in which $u_{w}$ varies as $b x^{m}$. Here $m$ is an arbitrary constant, not necessarily an integer. Such surface velocity variations are therefore required for the ODE (14) to be valid. Non-similar stretching sheet problems, which require the solutions to partial differential equations rather than ODEs, were considered by Jeng et al. [39] for Newtonian fluids.

It is worth mentioning here that in the absence of variable fluid properties, i.e., variable fluid viscosity parameter and the variable thermal conductivity parameter, Eqs. (14) and (15) reduce to those of Ishak et al. [36]; while for continuous moving surface in the absence of mixed convection parameter $\lambda$, for $\theta_{r}$ very large and constant magnetic field, Eqs. (14) and (15) reduces to those of Chakrabarthi and Gupta [37]; and Vajravelu [33] when $m=0$. In the presence of variable magnetic field and when there is no heat transfer, Eq. (14) reduces to that of Chiam [16]. Further when the variable thermal conductivity parameter and the magnetic parameter are absent, Eqs. (14) and (15) are similar to the ones studied by Grubka and Bobba [38].

The physical quantities of interest include the velocity components $u$ and $v$, the temperature distribution, the local surface heat flux $q_{w}(x)=-k_{\infty}(\partial T / \partial y)_{\text {at } y=0}$ or the Nusselt number $\mathrm{Nu}_{x}=h_{x} / k_{\infty}$ where $h=q_{w}(x) /\left(T_{w}-T_{\infty}\right)$, and the local friction coefficient $C_{f x}=\tau_{w}(x) / \rho_{\infty} u_{w}^{2} / 2$ with $\tau_{w}(x)=\mu_{\infty}(\partial u / \partial y)_{a t ~} y=0$ denoting the local wall shear stress. In terms of the transformation variables, the flow field, and the flow and heat transfer characteristics can be written as

$u=u_{w} f_{\eta}(\eta), \quad v=-\sqrt{\frac{2 \gamma_{\infty} b}{1+m}} x^{m-1 / 2}\left[\frac{m+1}{2} f(\eta)+\frac{m-1}{2} \eta f_{\eta}(\eta)\right]$,
$c_{f} \sqrt{\operatorname{Re}_{x}}=-\frac{\sqrt{2(m+1)} \theta_{r}}{\left(\theta_{r}-1\right)} f_{\eta \eta}\left(0, \theta_{r}\right), \quad \frac{\mathrm{Nu}}{\sqrt{\mathrm{Re}_{x}}}=-\sqrt{\frac{m+1}{2}} \theta_{\eta}\left(0, \theta_{r}\right)$
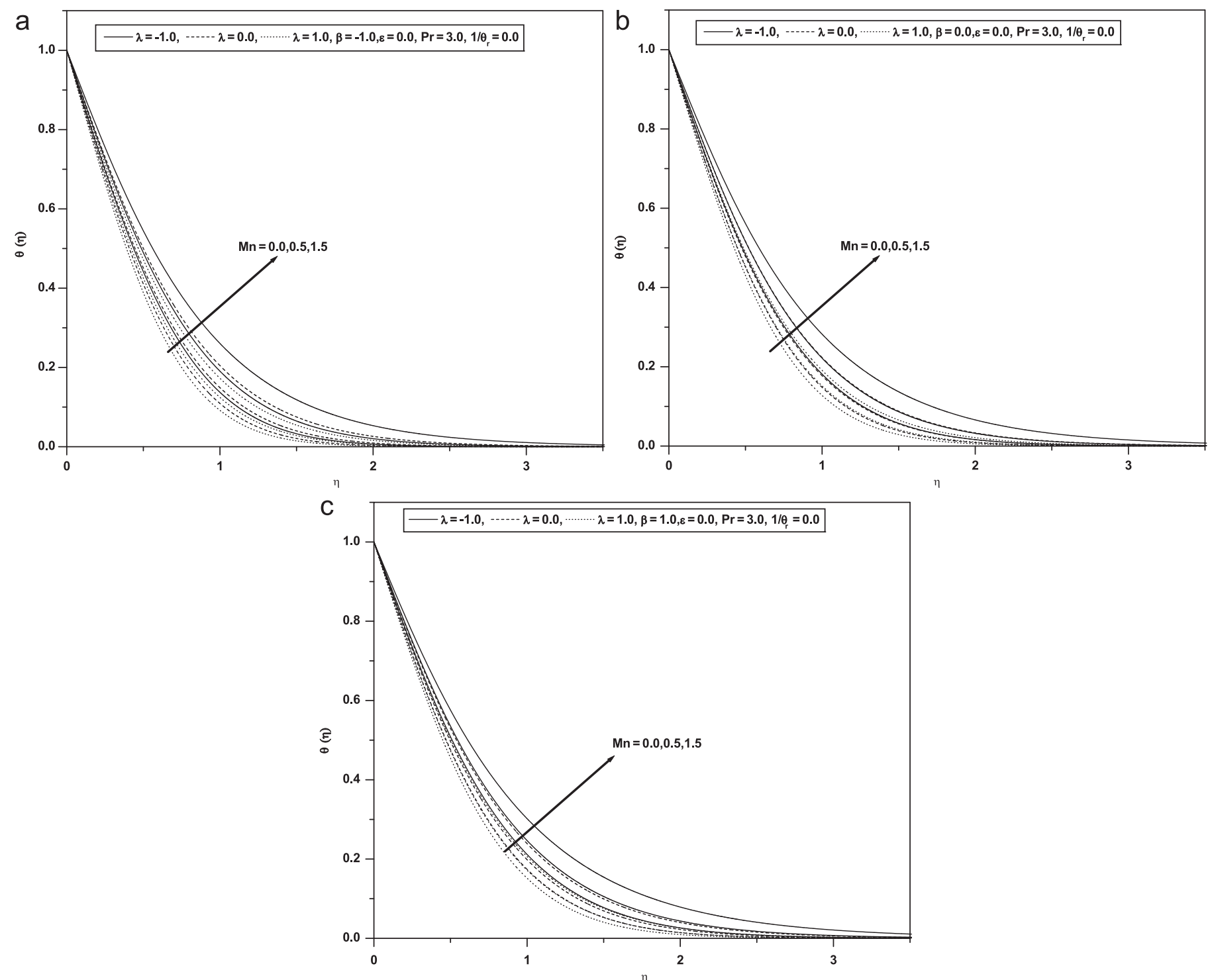

Fig. 4. (a-c) Temperature profiles for different values of magnetic parameter and mixed convection parameter. 


\section{Numerical procedure}

The coupled non-linear ordinary differential equations (14) and (15) together with the boundary conditions (16) and (17) are solved numerically by an efficient and accurate finite difference scheme known as Keller Box method (for details see Prasad et al. [9], Ishak et al. [36] and Cebeci and Bradshaw [40] and Keller [41]). This method is unconditionally stable and has a second order accuracy. For brevity, the details of the procedure are not presented here. It is worth mentioning that a uniform grid size of $\Delta \eta=0.01$ was found to be satisfactory in obtaining an accuracy up to six decimal places, for all the cases considered. To assess the accuracy of the present method, comparison of the skin friction and wall temperature gradient between the present results and the previously published results are made, for several special cases in which the mixed convection parameter and temperature dependent fluid properties are neglected.

\section{Results and discussion}

The influence of the temperature dependent fluid properties on laminar mixed convection, MHD boundary layer flow and heat transfer in an electrically conducting fluid over a non-linear stretching sheet is investigated numerically. Analytical solutions are obtained for the special case when $\theta_{r} \rightarrow \infty, m=1$ and $\lambda=0$. A numerical solution is warranted for the general case which is achieved by using a finite difference scheme known as Keller Box method. In order to have an understanding of the mathematical model, we present the numerical results graphically for the horizontal velocity and the temperature field, respectively, in Figs. 2 and 3 and Figs. 4-7; the surface velocity gradient and the wall temperature gradient are tabulated in Table 1 .

Figs. 2(a-c) present, respectively, the effects of the stretching parameter $(\beta<0),(\beta=0)$ and $(\beta>0)$, on the horizontal velocity profiles $f_{\eta}(\eta)$ for several sets of values of the magnetic parameter $M n$ and the mixed convection parameter $\lambda$. It is noticed that the horizontal velocity $f_{\eta}(\eta)$ decreases asymptotically to zero as the distance increases from the sheet. Fig. 2(a) illustrates the effects of the magnetic parameter $M n$ and mixed convection parameter $\lambda$ on the horizontal velocity profiles $f_{\eta}(\eta)$. It is observed that the horizontal velocity $f_{\eta}(\eta)$ decreases with increasing values of the magnetic parameter $M n$. It clearly indicates that the transverse magnetic field opposes the transport phenomena. This is due to the fact that the variation in $M n$ leads to the variation of the Lorentz force, and the Lorentz force produces more resistance to the transport phenomena. It is clearly seen from the Figs. 2(a-c), the momentum boundary layer thickness decreases as the magnetic parameter increases, and hence induces an increase (in absolute sense) in the surface velocity gradient $f_{\eta \eta}(0)$ at the surface (see Table 1). This phenomenon is even true with the increasing values of the mixed convection parameter $\lambda$. Physically $\lambda>0$ means heating of the fluid or cooling of the surface, $\lambda<0$ means cooling of the fluid or heating of the surface, and $\lambda=0$ corresponds to the absence of the mixed convection parameter. From the Fig. 2(a) we also notice that an increase in the value of the mixed convection parameter $\lambda$ leads to an increase in the horizontal velocity $f_{\eta}(\eta)$. Increase in $\lambda$ means an increase in the temperature difference $\left(T_{w}-T_{\infty}\right)$ which leads to an enhancement of the horizontal velocity $f_{\eta}(\eta)$ due to the enhanced convection, and thus an increase in the momentum boundary layer thickness. This observation is holds even for increasing values of the stretching parameter $\beta$. Fig. 2(d) depicts the horizontal velocity $f_{\eta}(\eta)$ for several sets of values of the stretching parameter $\beta$ and the mixed convection parameter $\lambda$. From the figure we observe that the effect of increasing values of the stretching parameter $\beta$ is to reduce the momentum boundary layer thickness, which tends to zero as the space variable $\eta$ increases from the boundary. Physically $(\beta<0)$ implies that the surface is decelerated from the extruded slit, $(\beta=0)$ implies the continuous movement of the flat

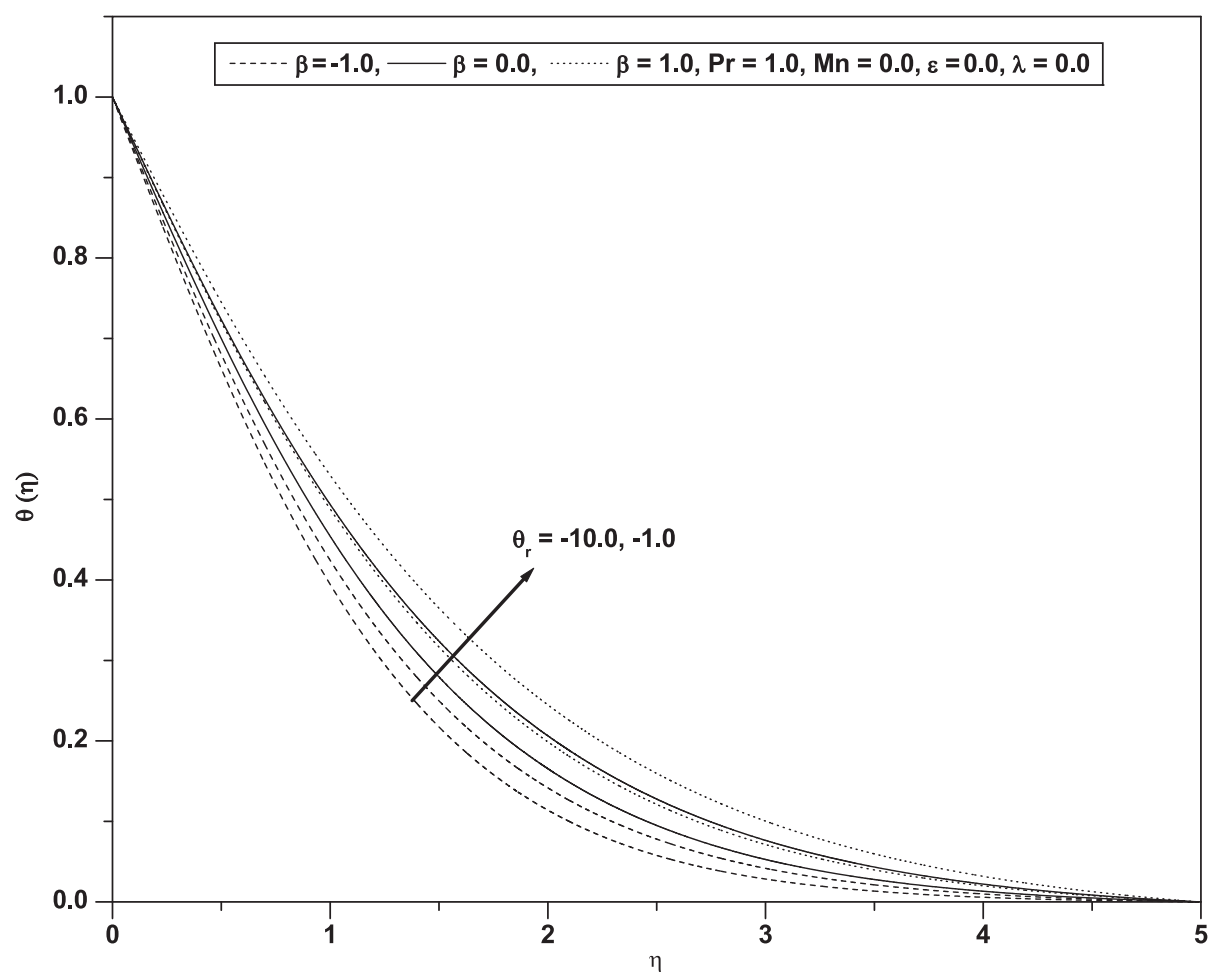

Fig. 5. Temperature profiles for different values of fluid viscosity parameter. 

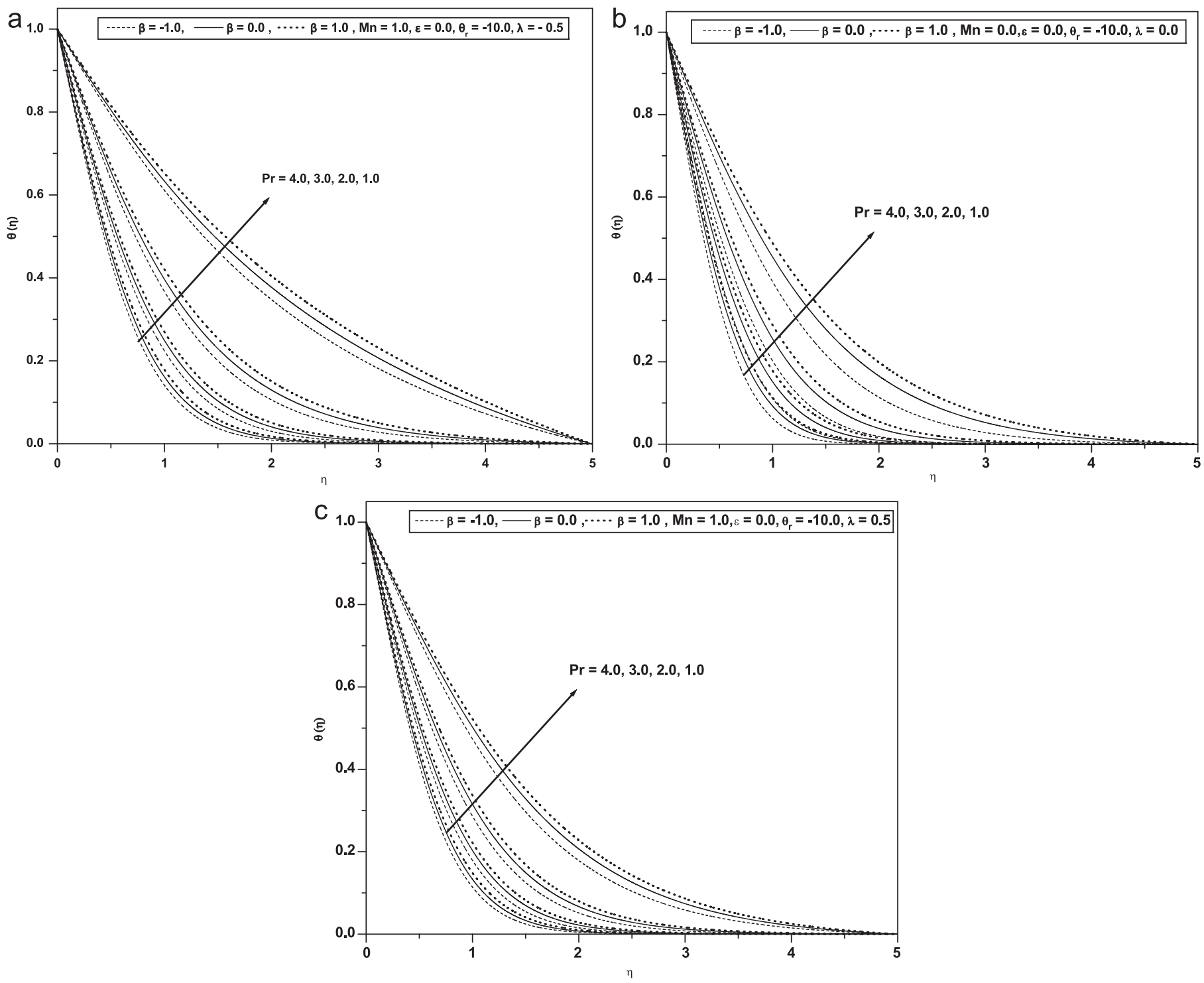

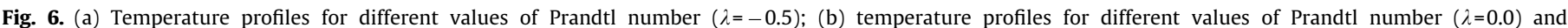
(c) temperature profiles for different values of Prandtl number $(\lambda=0.5)$.

surface, and $(\beta>0)$ implies that the surface is accelerated from the extruded slit. Horizontal velocity profiles decrease, disclosing the fact that the effect of stretching parameter $\beta$ is to decelerate the velocity and hence reduce the momentum boundary layer thickness.

Figs. 3(a-c), represent, respectively, the effects of the decelerating surface, the continuously moving surface and the accelerating surface from the extruded slit for different values of the fluid viscosity parameter $\theta_{r}$ and the mixed convection parameter $\lambda$. The effect of increasing values of the fluid viscosity parameter $\theta_{r}$ is to decrease the momentum boundary layer thickness and it asymptotically tends to zero in the free stream region. It is clearly seen that as $\theta_{r} \rightarrow 0$ the boundary layer thickness decreases and the velocity distribution becomes linear in shape for the higher values of the Prandtl number. This is because, for a given fluid with fixed $\gamma$, smaller $\theta_{r}$ implies higher temperature difference between the wall and the ambient fluid. The results presented in this paper demonstrate quite clearly that $\theta_{r}$, which is an indicator of the variable fluid viscosity parameter $\theta_{r}$ with temperature, has a substantial effect on the horizontal velocity $f_{\eta}(\eta)$ with in the boundary layer over a non-linearly stretching sheet as well as on the skin friction coefficient. This observation is true even for different values of the mixed convection parameter (see Figs. 3(a-c)).

The graphs for the temperature profiles $\theta(\eta)$ for different values of the parameters governing the mathematical model, are presented in Figs. 4-7. The general trend from the temperature profiles shows that the temperature distribution is unity at the wall and tends asymptotically to zero as the distance increases from the boundary. Fig. 4(a) explores the effects of the magnetic parameter $M n$ and the mixed convection parameter $\lambda$ on the temperature profile $\theta(\eta)$. It is observed that the effect of the magnetic parameter $M n$ is to increase the temperature $\theta(\eta)$. As explained above, the introduction of transverse magnetic filed to an electrically conducting fluid gives rise to a resistive force known as Lorentz force. This force forces the fluid to experience a resistance by increasing the friction between its layers, and due to this there is an increase in the temperature $\theta(\eta)$. This behavior is true even for the increasing values of the mixed convection parameter $\lambda$. Increasing values of the mixed convection parameter $\lambda$ results in a decrease in the thermal boundary layer thickness; this is associated with an increase in the magnitude of the wall 


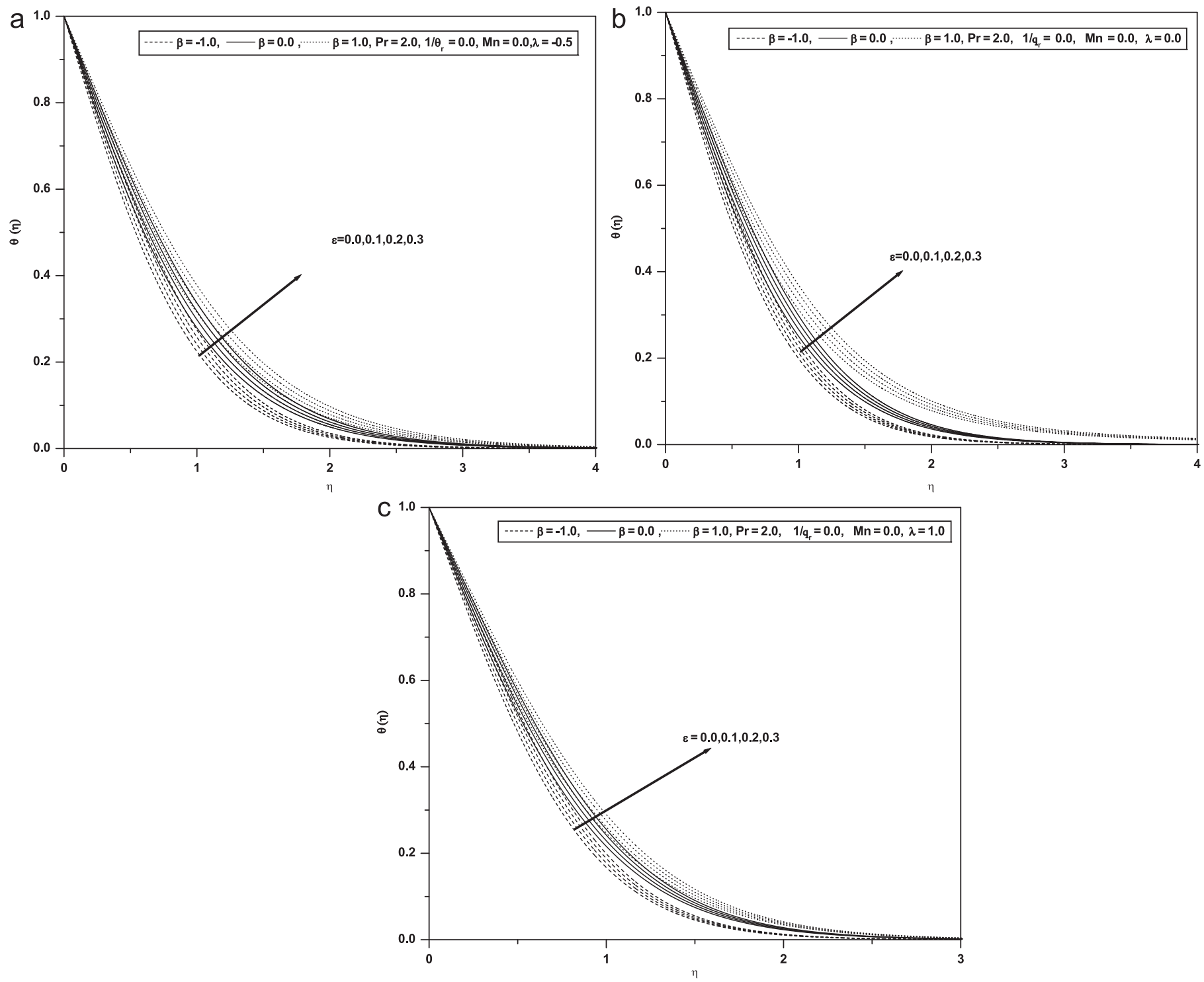

Fig. 7. $(a-c)$ Temperature profiles for different values of variable thermal conductivity parameter.

temperature gradient and hence results in an increase in the surface heat transfer. This observation is true even when the surface is decelerating (see Fig. 4(a)), continuously moving (see Fig. 4(b)) and accelerating (see Fig. 4(c)) from the extruded slit.

Fig. 5 shows the effect of the variable viscosity parameter $\theta_{r}$ on the temperature profile $\theta(\eta)$. From this figure we see that an increase in the value of the variable viscosity parameter $\theta_{r}$ is to enhance the value of the temperature $\theta(\eta)$. This is due to the fact that an increase in the value of $\theta_{r}$ results in an increase in the thermal boundary layer thickness, which results in an increase in the temperature $\theta(\eta)$. This is very much noticeable for the decelerating surface case compared to the continuously moving and the accelerating surface cases.

Figs. $6(a-c)$ and $7(a-c)$, respectively, represent the temperature $\theta(\eta)$ for several sets of values of the Prandtl number Pr and variable thermal conductivity parameter $\varepsilon$ for the increasing values of stretching parameter and the mixed convection parameter. From the graphical representation we see that the effect of an increase in Prandtl number $\mathrm{Pr}$ is to decrease the temperature $\theta(\eta)$. This is because of the fact that the thermal boundary layer thickness decreases with an increase in the
Prandtl number. This phenomenon is true even for zero/non-zero values of the mixed convection parameter. The effect of stretching parameter is to increase the temperature profile in the presence of fluid viscosity parameter. The effect of the variable thermal conductivity parameter on the temperature profile $\theta(\eta)$ for increasing values of the mixed convection parameter $\lambda$ is shown graphically in Figs. $7(a-c)$ for different values of stretching parameter $\beta$. From these graphs we observe that the temperature distribution is lower throughout the boundary layer in the absence of variable thermal conductivity parameter and becomes higher when we increase the values of the variable thermal conductivity parameter. In either case the temperature distribution $\theta(\eta)$ tends to zero as the space variable increases from the boundary. This is due to the fact that the assumption of temperature dependent thermal conductivity implies reduction in the magnitude of the transverse velocity by a quantity $\partial / \partial y(k(T))$ which can be seen from Eq. (8). The effects of all the physical parameters involved, on the surface velocity gradient and on the wall temperature gradient, respectively at the wall are recorded in Table 1 . It is of interest to note that the effect of increasing values of the magnetic parameter, the variable 
Table 1

Skin friction and wall temperature gradient for different values of the physical parameters

\begin{tabular}{|c|c|c|c|c|c|c|c|c|c|c|}
\hline \multirow[t]{2}{*}{ Pr } & \multirow[t]{2}{*}{$\theta_{r}$} & \multirow[t]{2}{*}{$\varepsilon$} & \multirow[t]{2}{*}{$\beta$} & \multirow[t]{2}{*}{ Mn } & \multicolumn{2}{|l|}{$G r=-0.5$} & \multicolumn{2}{|l|}{$\mathbf{G r}=\mathbf{0 . 0}$} & \multicolumn{2}{|l|}{$\mathrm{Gr}=0.5$} \\
\hline & & & & & $f_{\eta \eta}(0)$ & $\theta_{\eta}(0)$ & $f_{\eta \eta}(0)$ & $\theta_{\eta}(0)$ & $f_{\eta \eta}(0)$ & $\theta_{\eta}(0)$ \\
\hline \multirow[t]{12}{*}{1} & $\rightarrow 0$ & - & -1 & & -0.56622 & -0.62184 & -0.02045 & -0.70756 & -0.42326 & -0.7596 \\
\hline & & & & 0.5 & -0.96033 & -0.55525 & -0.52727 & -0.63291 & -0.45193 & -0.68596 \\
\hline & & & & 1 & -1.21335 & -0.51999 & -0.85171 & -0.58547 & -0.51951 & -0.63589 \\
\hline & & & & 1.5 & -1.41432 & -0.49656 & -1.09799 & -0.55427 & -0.80119 & -0.59962 \\
\hline & & & 0 & 0 & -1.02406 & -0.56213 & -0.63004 & -0.63004 & -0.3094 & -0.67823 \\
\hline & & & & 0.5 & -1.27277 & -0.52307 & -0.92798 & -0.57857 & -0.63004 & -0.63004 \\
\hline & & & & 1 & -1.46802 & -0.49848 & -1.16337 & -0.54139 & -0.88578 & -0.59235 \\
\hline & & & & 1.5 & -1.63595 & -0.48063 & -1.35947 & -0.51314 & -1.10103 & -0.56215 \\
\hline & & & 1 & 0 & -1.32827 & -0.52739 & -1.00014 & -0.58728 & -0.73454 & -0.6328 \\
\hline & & & & 0.5 & -1.52018 & -0.50045 & -1.22491 & -0.54855 & -0.96913 & -0.59648 \\
\hline & & & & 1 & -1.68385 & -0.482 & -1.41424 & -0.51902 & -1.1713 & -0.56663 \\
\hline & & & & 1.5 & -1.83065 & -0.46781 & -1.58114 & -0.49567 & -1.35042 & -0.54183 \\
\hline Pr & Mn & $\varepsilon$ & $\boldsymbol{\beta}$ & $\theta_{r}$ & $f_{\eta \eta}(0)$ & $\theta_{\eta}(0)$ & $f_{\eta \eta}(0)$ & $\theta_{\eta}(0)$ & $f_{\eta \eta}(0)$ & $\theta_{\eta}(0)$ \\
\hline \multirow[t]{12}{*}{1} & 0 & 0 & -1 & -10 & -0.63582 & -0.60653 & -0.00548 & -0.70287 & 0.48594 & -0.76057 \\
\hline & & & & -5 & -0.70857 & -0.59014 & -0.00601 & -0.69862 & 0.53109 & -0.76034 \\
\hline & & & & 1 & -1.41552 & -0.39608 & -0.00976 & -0.66543 & 0.8985 & -0.75826 \\
\hline & & & & -0.1 & -3.21152 & -0.74365 & -0.00111 & -0.45364 & 5.48756 & -0.73902 \\
\hline & & & 0 & -10 & -1.01061 & -0.54625 & -0.66899 & -0.62337 & -0.36209 & -0.67502 \\
\hline & & & & -5 & -1.18814 & -0.52934 & -0.70565 & -0.61698 & -0.33059 & -0.67204 \\
\hline & & & & 1 & -1.74961 & -0.44908 & -0.9417 & -0.5739 & -0.3651 & -0.65427 \\
\hline & & & & -0.1 & -5.48348 & -0.39559 & -2.14381 & -0.39409 & -0.12308 & -0.61214 \\
\hline & & & 1 & -10 & -1.42171 & -0.51038 & -1.05943 & -0.57985 & -0.94146 & -0.34425 \\
\hline & & & & -5 & -1.51586 & -0.49097 & -1.11405 & -0.57284 & -0.96844 & -0.34396 \\
\hline & & & & 1 & -2.02807 & -0.50682 & -1.46912 & -0.52772 & -1.01504 & -0.60194 \\
\hline & & & & -0.1 & -5.06977 & -0.72464 & -3.50033 & -0.29333 & -1.90573 & -0.54923 \\
\hline Mn & $\theta_{r}$ & $\varepsilon$ & Gr & Pr & $\beta=-1.0$ & & $\beta=0.0$ & & $\beta=1.0$ & \\
\hline \multirow[t]{4}{*}{0.0} & -10.0 & & 0 & 1 & -0.00548 & -0.70287 & -0.66899 & -0.62337 & -1.05943 & -0.57985 \\
\hline & & & & 2 & -0.00553 & -1.05627 & -0.6724 & -0.9581 & -1.06369 & -0.90179 \\
\hline & & & & 3 & -0.00552 & -1.32203 & -0.67454 & -1.21633 & -1.06659 & -1.15522 \\
\hline & & & & 4 & -0.00551 & -1.54338 & -0.67605 & -1.4331 & -1.06876 & -1.36913 \\
\hline \multirow[t]{4}{*}{1} & -10 & 0 & -0.5 & 1 & -1.32926 & -0.42453 & -1.58911 & -0.39907 & -1.81232 & -0.37716 \\
\hline & & & & 2 & -1.22306 & -0.75998 & -1.50757 & -0.71904 & -1.74382 & -0.6865 \\
\hline & & & & 3 & -1.16659 & -1.02383 & -1.4635 & -0.97866 & -1.70702 & -0.94319 \\
\hline & & & & 4 & -1.134 & -1.2383 & -1.43794 & -1.1905 & -1.68569 & -1.15308 \\
\hline \multirow[t]{4}{*}{1} & -10 & 0 & 0.5 & 1 & -0.52926 & -0.58287 & -0.92532 & -0.54753 & -1.22753 & -0.52306 \\
\hline & & & & 2 & -0.62312 & -0.87599 & -0.99078 & -0.83105 & -1.27821 & -0.79808 \\
\hline & & & & 3 & -0.67275 & -1.10962 & -1.02905 & -1.06075 & -1.30998 & -1.02408 \\
\hline & & & & 4 & 0.704274 & -1.30845 & -1.05462 & -1.2573 & -1.33201 & -1.21847 \\
\hline Mn & $\theta_{r}$ & pr & Gr & $\varepsilon$ & $\beta=-1.0$ & & $\beta=0.0$ & & $\beta=1.0$ & \\
\hline \multirow[t]{12}{*}{0} & -10 & 1 & 0 & 0 & -0.00548 & -0.70287 & -0.66899 & -0.62337 & -1.05943 & -0.57985 \\
\hline & & & & 0.1 & -0.00547 & -0.65577 & -0.66862 & -0.58048 & -1.05896 & -0.5394 \\
\hline & & & & 0.2 & -0.00547 & -0.61576 & 0.66828 & -0.54408 & -1.05854 & -0.50511 \\
\hline & & & & 0.3 & -0.00546 & -0.58126 & -0.66796 & -0.51274 & -1.05816 & -0.47561 \\
\hline & & & -0.5 & 0 & -1.42171 & -1.51038 & -1.10608 & -0.54625 & -0.63582 & -0.60653 \\
\hline & & & & 0.1 & -1.43631 & -0.46795 & -1.12326 & -0.50211 & -0.66361 & -0.5579 \\
\hline & & & & 0.2 & -1.4518 & -0.43117 & -1.14045 & -0.46429 & -0.69118 & -0.51612 \\
\hline & & & & 0.3 & -1.46874 & -0.39852 & -1.15764 & -0.43145 & -0.71838 & -0.47974 \\
\hline & & & 0.5 & 0 & 0.48593 & -0.76057 & -0.32088 & -0.67502 & -0.7717 & -0.62854 \\
\hline & & & & 0.1 & 0.50155 & -0.71275 & -0.31175 & -0.63422 & -0.76509 & -0.58735 \\
\hline & & & & 0.2 & 0.51674 & -0.67223 & -0.30304 & -0.59449 & -0.75888 & -0.55246 \\
\hline & & & & 0.3 & 0.53155 & -0.63738 & -0.29472 & -0.56274 & -0.75304 & -0.52248 \\
\hline
\end{tabular}

viscosity parameter and the stretching parameter is to decrease the skin friction and to increase the wall temperature gradient. The effect of increasing values of the mixed convection parameter and the Prandtl number is to increase the skin friction and to decrease the wall temperature gradient, respectively.

\section{Conclusion}

The mathematical model for the problem of variable fluid properties on the laminar mixed convection adjacent to a vertical stretching sheet in the presence of variable magnetic field has been analyzed numerically. The governing equations were developed and transformed to coupled non-linear ordinary differential equations by using an appropriate transformations and then solved numerically by Keller Box method. A systematic study is made on the effects of the parameters involved in the laminar mixed convection heat transfer over a non-linear stretching sheet. The following conclusions can be drawn from the computed numerical values:

1. The effect of increasing values of the magnetic parameter and the stretching parameter is to decrease the momentum boundary layer thickness and to increase the thermal boundary layer thickness. 
2. The effect of increasing values of the variable viscosity parameter and the mixed convection parameter is to increase the momentum boundary layer as well as the thermal boundary layer thickness.

3. The effect of the Prandtl number is to decrease the thermal boundary layer thickness.

4. In the presence of the magnetic field, skin friction increases with an increase in the stretching rate parameter. But the rate of heat transfer decreases with an increase in the stretching rate parameter and it decreases with a decrease in the stretching parameter.

5. In the presence of the stretching parameter the skin friction decreases with an increase in the magnetic parameter; however, the rate of heat transfer increases with an increase in the magnetic parameter.

6. Of all the parameters considered, the variable viscosity parameter has the strong effect on the drag, heat transfer characteristics, the horizontal velocity and the temperature field in the boundary layer of a non-linearly stretching sheet.

\section{References}

[1] T. Altan, S. Oh, H. Gegel, Metal Forming Fundamentals and Applications, American Society of Metals, Metals Park, OH, 1979.

[2] E.G. Fisher, Extrusion of Plastics, Wiley, New York, 1976

[3] Z. Tadmor, I. Klein, Engineering Principles of Plasticating Extrusion, Polymer Science and Engineering Series, Van Nostrand Reinhold, New York, 1970.

[4] T. Watanabe, I. Pop, Thermal boundary layers in magnetohydrodynamic flow over a flat plate in the presence of a transverse magnetic field, Acta Mech. 105 (1994) 233-238.

[5] H.I. Andersson, MHD flow of a visco-elastic fluid past a stretching surface, Acta Mech. 95 (1992) 227-230.

[6] M.S. Abel, A. Joshi, R.M. Sonth, Heat transfer in MHD visco-elastic fluid flow over a stretching surface, ZAMM 81 (2001) 691-698.

[7] P.S. Datti, K.V. Prasad, M. Subhas Abel, A. Joshi, MHD visco-elastic fluid flow over a non-isothermal stretching sheet, Int. J. Eng. Sci. 42 (2004) 935-946.

[8] E.M. Abo-Eldahab, A.M. Salem, MHD free convection flow of a non-Newtonian power law fluid at a stretchinh surface with a uniform free stream, Appl. Math. Comput. 169 (2005) 806-818.

[9] K.V. Prasad, P.S. Datti, D. Pal, MHD flow and heat transfer in the flow of a power law fluid over a non-isothermal stretching sheet, Int. J. Non-Linear Sci. Numer. Simulation 14 (2009) 2178-2189.

[10] K.V. Prasad, K. Vajravelu, Heat transfer in the MHD flow of a power law fluid over a non-isothermal stretching sheet, Int. J. Heat Mass Transfer 52 (2009) 4956-4965.

[11] T.S. Chen, F.A. Strobel, Buoyancy effects in boundary layer adjacent to a continuous moving horizontal flat plate, ASME J. Heat Transfer 102 (1980) $170-172$.

[12] A. Moutsoglou, T.S. Chen, Buoyancy effects in boundary layer on inclined continuous moving sheets, ASME J. Heat Transfer 102 (1980) 371-373.

[13] M.V. Karwe, Y. Jaluria, Numerical simulation of thermal transport associated with a continuously moving flat sheet in materials processing, ASME J. Heat Transfer 113 (1991) 612-619.

[14] G. Malarvizhi, G. Ramanaiah, I. Pop, Free and mixed convection about a vertical plate with prescribed temperature or heat flux, ZAMM 74 (1994) 129-131.

[15] K. Vajravelu, Convection heat transfer at a stretching sheet with suction or blowing, Int. J. Math. Anal. Appl. 188 (1994) 1002-1011.
[16] C.H. Chen, Laminar mixed convection adjacent to vertical continuously stretching sheets, Heat Mass Transfer 33 (1998) 471-476.

[17] M. Ali, F. Al-Yousef, Laminar mixed convection boundary layers induced by a linearly permeable surface, Int. J. Heat Mass Transfer 45 (2002) 4241-4250.

[18] K. Vajravelu, A. Hadjinicolaou, Convective heat transfer in an electrically conducting fluid at a stretching surface with uniform heat source, Int. J. Eng. Sci. 35 (1997) 1237-1244.

[19] M.A. EL-Hakiem, A.A. Mohammadein, S.M.M. EL-Kabeir, Joule heating effects on magnetohydrodynamic free convection flow of a micropolar fluid, Int Commun. Heat Mass Transfer 26 (1999) 219-227.

[20] A.J. Chamkha, Hydromagnetic three dimensional free convection on a vertical stretching surface with heat generation/absorption. Int. J. Heat Fluid Flow 20 (1999) 84-92.

[21] E.M. Abo-Eldahab, Hydromagnetic three dimensional flow over a stretching surface with heat and mass transfer, Heat Mass Transfer 41 (2005) 734-743.

[22] A. Ishak, R. Nazar, I. Pop, Magnetohydrodynamic stagnation point flow towards a stretching vertical sheet, Magnetohydrodynamics 42 (2006) 17-30.

[23] H. Herwig, G. Wickern, The effect of variable fluid properties on laminar boundary layer flow, warme-und-stoffubertragung 20 (1986) 47-57.

[24] F.C. Lai, F.A. Kulacki, The effect of variable fluid viscosity on convective heat transfer along vertical surface in a saturated porous medium, Int. J. Heat Mass Transfer 33 (1990) 1028-1031.

[25] T.S. Takhar, S. Nitu, I. Pop, Boundary layer flow due to a moving a plate: variable fluid properties, Acta Mech. 90 (1991) 37-42.

[26] I. Pop, R.S.R. Gorla, M. Rashidi, The effect of variable viscosity on flow and heat transfer to a continuous moving flat plate, Int. J. Eng. Sci. 30 (1992) 1-6.

[27] I.A. Hassanien, The effect of variable viscosity on flow and heat transfer on a continuous stretching surface, ZAMM 77 (1997) 876-880.

[28] M. Subhas Abel, S.K. Khan, K.V. Prasad, Study of visco-elastic fluid flow and heat transfer over a stretching sheet with variable fluid viscosity, Int. J. NonLinear Mech. 37 (2002) 81-88.

[29] M.A Seedeek, Finite element method for the effects of chemical reaction, variable viscosity, thermophoresis and heat generation/absorption on a boundary layer hydromagnetic flow with heat and mass transfer over a heat surface, Acta Mech. 177 (2005) 1-18.

[30] M.E. Ali, The effect of variable viscosity on mixed convection heat transfer along a vertical moving surface, Int. J. Therm. Sci. 45 (2006) 60-69.

[31] H.I. Andersson, J.B. Aarseth, Sakiadis flow with variable fluid properties, Int. J. Eng. Sci. 45 (2007) 554-561.

[32] T.C. Chiam, Heat transfer with variable thermal conductivity in a stagnation point towards a stretching sheet, Int. Commun. Heat Mass Transfer 23 (1996) 239-248.

[33] K. Vajravelu, Viscous flow over a nonlinearly stretching sheet, Appl. Math Comput. 124 (2001) 281-288.

[34] T.C. Chiam, Hydromagnetic flow over a surface with a power law velocity, Int J. Eng. Sci. 33 (1995) 429-435.

[35] S.P. Anjali Devi, M. Thiyagarajan, Steady non-linear hydromagnetic flow and heat transfer over a stretching surface with variable temperature, Heat Mass Transfer 42 (2006) 671-677.

[36] A. Ishak, R. Nazar, I. Pop, Magnetohydrodynamic stagnation point flow towards a stretching vertical sheet, Magnetohydrodynamics 42 (2006) 17-30.

[37] A. Chakrabart, A.S. Gupta, Hydro magnetic flow and heat transfer over a stretching sheet, O. Appl. Math. 37 (1979) 73-78.

[38] L.J. Grubka, K.M. Bobba, Heat transfer characteristics of a continuous stretching surface with variable temperature, ASME J. Heat Transfer 107 (1985) 248-250.

[39] D.R. Jeng, T.C.A. Chang, K. Dewitt, Momentum and heat transfer on a continuous moving surface, ASME J. Heat Transfer 108 (1986) 532-539.

[40] T. Cebeci, P. Bradshaw, Physical and Computational Aspects of Convective Heat Transfer, Springer, New York, 1984.

[41] H.B. Keller, Numerical Methods for Two-point Boundary Value Problems, Dover, New York, 1992.

[42] J.B. McLeod, K.R. Rajagopal, On uniqueness of flow of a Navier-Stokes fluid due to a stretching boundary, Arch. Rat. Mech. Anal. 98 (1987) 386-393. 